\title{
LA PIEDRA NOIRE DE COCHINCHINE
}

\author{
Par SOUCHARD et NGUYEN-VAN-HUONG
}

En recherchant les mycoses du cuir chevelu chez les Annamites de Cochinchine, nous avons constaté qu'un grand nombre d'entre eux étaient porteurs de nodosités des cheveux.

Ces nodosités, qui sont toutes de nature mycosique, ne sont pas uniformément provoquées par le développement à la surface du cheveu du même champignon. Il en existe, en effet, plusieurs variétés, dues au développement de champignons différents.

Les plus répandues et celles qui offrent le plus d'intérêt sont provoquées par un champignon du genre Piedraia, qui n'a pas encore été signalé, à notre connaissance, en Indochine et qui fait l'objet de cette étude.

Description des nodosités. - Les cheveux parasités par ce champignon, intacts dans leur couleur et dans leur résistance, présentent le long de leurs parois de petites nodosités, très noires et très dures. Ces nodosités, qui peuvent atteindre 1 à $2 \mathrm{~mm}$. de long sur 300 à $400 \mu$ d'épaisseur, sont assez irrégulières dans leur forme et dans leurs dimensions. Le plus souvent allongées, elles engainent le cheveu sur la totalité ou sur une partie seulement de son pourtour.

Lorsqu'on examine ces nodosités au microseope, après traitement au chlorallactophénol ou mieux à la potasse à $400 / 0$, on se rend compte qu'elles sont formées par des filaments cloisonnés, soudés les uns aux autres en un stroma fortement coloré. Nous avons retrouvé tous les détails qui ont été si minutieusement décrits par Horta (1911) puis par Langeron (1929 et 1936) et par Brumpt et Langeron (1934).

A la coupe, on peut voir que les filaments, qui ne pénètrent pas, à proprement parler, dans le cheveu, rayonnent du centre vers la périphérie des nodosités.

En examinant ces dernières aux différents stades de leur évolution, on voit que le champignon parasite commence à se développer entre l'épidermicule du cheveu, qu'il soulève, et la zone corticale, qui n'est pas pénétrée. Lorsque la nodosité a atteint un certain volume, l'épidermicule éclate, laissant le parasite à nu.

A l'examen microscopique du cheveu parasité, après traitement

Annales de Parasitologie, T. XV, $\mathrm{N}^{\circ} 6 .-1^{\text {er }}$ novembre 1937 , p. 539-543. 
par la potasse, on remarque que les nodosités les plus évoluées ne présentent pas un aspect uniforme. Elles sont parsemées irrégulièrement de petites zones arrondies, claires, à bords flous, qui tranchent sur leur couleur générale fohcée et leur donnent un aspect bigarré. Certaines de ces zones claires sont situées sur le bord des nodosités et semblent s'ouvrir à l'extérieur, bien qu'il n'y ait pas d'ostioles nettement délimités. Au niveau de ces zones, on n'aperçoit pas le carrelage des éléments mycéliens, mais un magma d'où émergent des formations arrondies ou piriformes.

$\mathrm{Si}$, après traitement prolongé à la potasse, on écrase entre lame

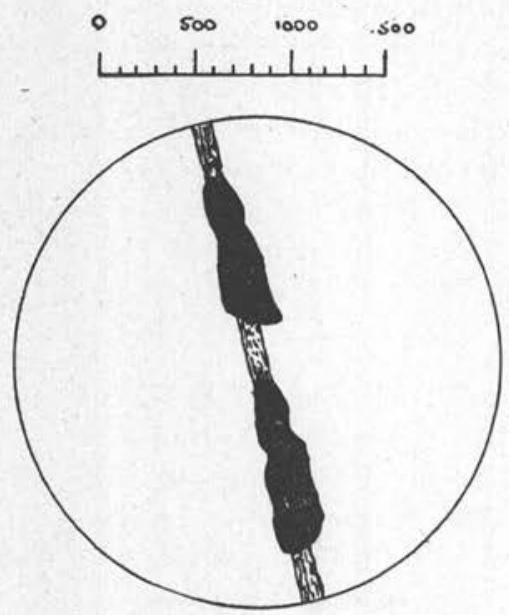

Fig. 1. - Nodosités piédriques traitées par le lactophénol.
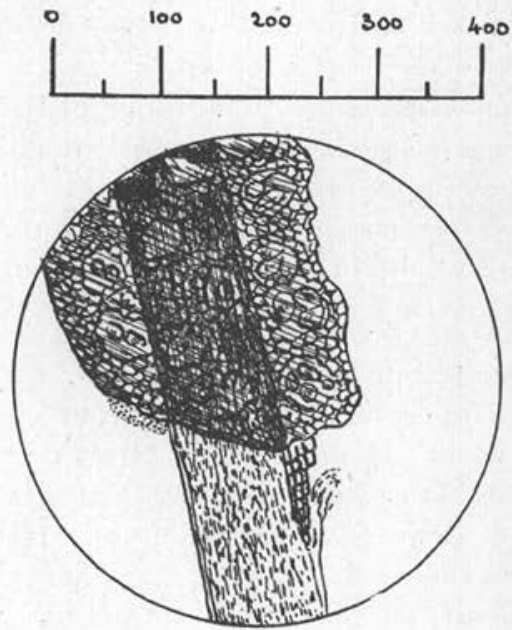

Fig. 2. - Nodosité piédrique traitée par la potasse à $40 \mathrm{p} .100$.

et lamelle une de ces nodosités, ayant atteint un certain développement, on observe plus aisément le contenu de ces zones claires.

Au milieu de débris, composés surtout d'articles mycéliens, on aperçoit des corps bien délimités, arrondis ou ovalaires, de dimensions variées, qui peuvent atteindre une longueur maximum de 30 à $35 \mu$ sur 18 à $20 \mu$ de large.

Ces corps, qui présentent une double enveloppe et sont les asques, si bien décrits par Horta (1911), renferment 6 à 8 ascospores. Cellesci sont arrondies, dans les asques les plus jeunes, allongées en forme de bananes et enroulées les unes sur les autres dans les asques mùrs. Ces ascospores, qu'on peut observer en liberté à côté des asques rompus, ont de 25 à $30 \mu$ de long sur 4 à $5 \mu$ d'épaisseur et portent, à chacune de leurs extrémités, un filament d'environ 6 à $9 \mu$ de longueur. 
A côté des asques, il est possible encore de voir de grandes cellules, arrondies ou piriformes, de 10 à $30 \mu$ de longueur sur 8 à $10 \mu$ de largeur, entourées d'une paroi épaisse et qui sont vraisemblablement les cellules mères des asques.

Culture. - Après traitement des cheveux parasités à l'éther pendant 10 à 15 minutes, on obtient, sur gélose glycosée à 6 pour

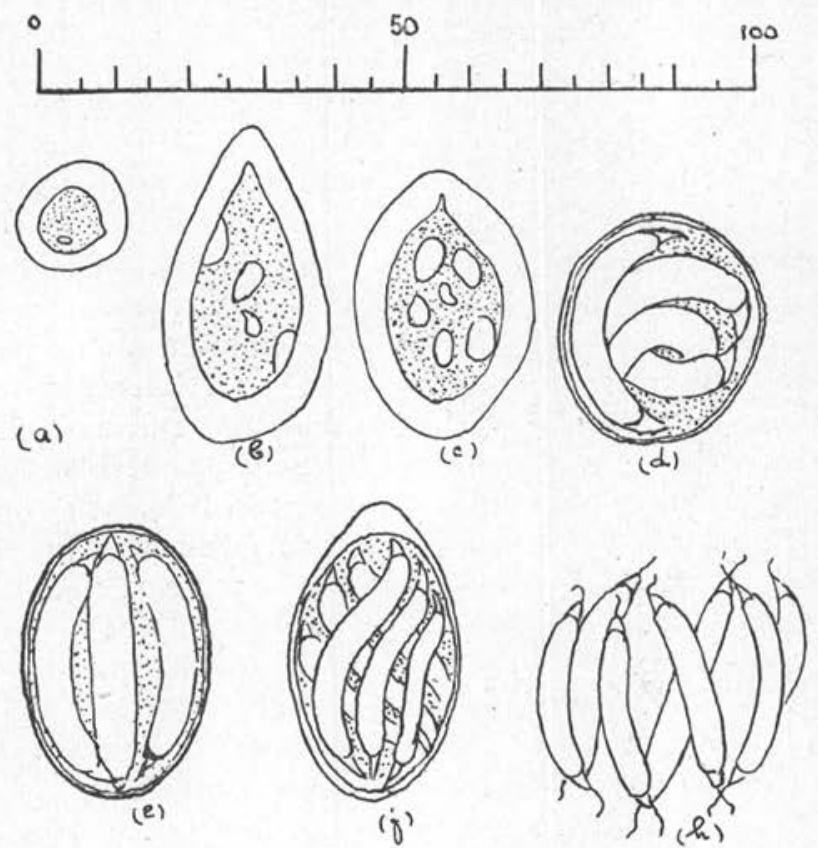

Fig. 3. - Asques et ascospores de la piedra de Cochinchine. $a, b, c$, cellules mères des asques ; $d, e, f$, asques mûrs ; $h$, ascospores.

cent, par ensemencement de ces nodosités, la culture d'un champignon qui présente les caractéristiques suivantes :

Colonie arrondie, noire, sèche, couverte d'un léger duvet d'hyphes aériennes de couleur plus claire, bordée d'un liséré brunâtre et qui ne fait pas saillie à la surface de la gélose, mais s'enfonce dans le substratum, auquel elle adhère fortement en un dôme arrondi d'aspect pelucheux. Après une vingtaine de jours de culture à $22^{\circ}$, cette colonie a atteint son complet développement.

En la dissociant dans le lacto-phénol, on voit qu'elle est formée de filaments mycéliens cloisonnés, ramifiés, qui présentent des chlamydospores, mais pas de fructifications proprement dites. 
Par repiquages successifs d'un fragment de cette colonie sur gélose glycosée à 6 pour cent, il est possible de conserver indéfiniment les souches de ce champignon.

Repiqué sur pomme de terre et surtout sur carotte, il se développe également en colonies noires, très dures, surmontées au centre d'un fin duvet brun clair et très adhérentes au milieu.

Ce champignon est l'agent causal des nodosités. Si on examine en effet ces dernières sous lamelle au microscope, dès le début de leur culture, on voit les filaments mycéliens émaner régulièrement de tout le pourtour de leurs parois et non d'une autre partie du cheveu.

Nous n'avons pas obtenu d'inoculation positive sur cobaye en partant d'une colonie noire, mais les conditions hygrométriques (expérience faite à Dalat par temps sec) n'étaient vraisemblablement pas favorables. D'autre part, il est permis de supposer que le champignon, agent pathogène des nodosités, possède une affinité élective pour le cheveu et que la contamination de ce dernier ne peut s'effectuer que par l'intermédiaire des éléments de fructification, que nous n'avons pas observés dans nos cultures.

A còté du champignon que nous venons de décrire, on obtient très fréquemment, en ensemençant des nodosités, des colonies blanc jaunâtre, glabres, exubérantes, à surface vermiculée et qui sont formées par un Trichosporum. Nous pensons que ce champignon ne jouie aucun rôle dans le développement des nodosités dont nous venons de parler. Nous avons bien constaté qu'il est susceptible de développer, à lui seul, sur le cheveu, des nodosités mycosiques, mais d'un tout autre aspect que celles de la piedra noire où il ne doit être considéré que comme un saprophyte, comme Chavarria et Rotter (1933) l'ont reconnu en Colombie.

Discussion. - Les nodosités des cheveux, que nous avons observées en Cochinchine et qui font l'objet de cette étude, présentent tous les caractères de celles qui ont été décrites pour la première fois par Horta en 1911 à Rio de Janeiro sous le nom de Piedra du Brésil.

Comme la piedra brésilienne, strictement localisée aux cheveux, la piedra de Cochinchine est caractérisée par le développement, uniquement sur des cheveux, de petites nodosités très noires et très dures, qui sont provoquées par la croissance en surface d'un champignon, formant autour du cheveu un ascostroma (Langeron 1929) pigmenté et cutinisé, dans lequel, à la maturité, apparaissent des asques, contenant de 6 à 8 ascospores, allongées et pourvues d'un filament à chacune de leurs extrémités.

Le champignon, agent de cette affection du cheveu, a été obtenu en culture pure par Horta, dès 1911. Les descriptions qu'il en a 
données rappellent tout à fait les caractères présentés par le champignon que nous avons isolé des nodosités de la piedra cochinchinoise.

Nous pensons donc avoir affaire, en Cochinchine, à une maladie identique à la piedra brésilienne.

Nous rappelons à ce sujet que le champignon, agent de la piedra brésilienne, nommé par Brumpt, en 1913, Trichosporum hortai, a été classé par Da Fonseca et Leao dans un genre nouveau, que ces auteurs ont nommé Piedraia et que Langeron (1929) range dans le groupement des Astérinées, ordre des Mycrothyriales, famille des Mycrothyriacées.

Comme la plupart des Astérinées, ce champignon ne serait susceptible de développement que dans. les régions du globe où il tombe au moins un mètre de pluie par an et qu'Arnaud (1918) a nommé pour cela régions à climat astérinéen. Le climat de Cochinchine, très humide et très chaud, ne pouvait que convenir au développement de la piedra noire.

L'enquête à laquelle nous nous sommes livrés nous a montré que cette affection du cheveu, très répandue dans le milieu annamite, était nettement contagieuse et que la contagion devait s'effectuer par les instruments utilisés par les coiffeurs, l'affection paraissant se limiter aux Annamites fréquentant certaines boutiques particulièrement infectées.

\section{RÉSUMÉ}

Découverte en Cochinchine d'un type de piedra noire paraissant identique, par ses caractères cliniques, macroscopiques, microscopiques et culturaux, à la piedra noire brésilienne.

\section{BiBLIOGRAPHIE}

Arnaud (G.). - Les astérinées. Thèse Fac. des Sciences, Paris, 1918.

Brumpt (E.) et Jangeron (M.). - Considérations sur la piecira de l'Amérique du Sud à l'occasion d'un cas provenant du Venezuela. Description d'une espèce nouvelle, Piedraia venezuelensis n. sp. Ann. de paras., XII, 1934 , p. $134-161$.

Chavarris (P.) et Rotter (W.). - Die kolumbianische Piedra. Arch. f. Schiffs. Trop. Hyg., XXXVII, 1933, p. 73-87.

Honta (P.). - Sobre uma nova forma de piedra. Mem. Inst. O. Cruz., III, 1911, p. 86-107.

Langeron (M.). - Les astérinées parasites de l'homme. La piedra. Ann. de paras., VII, 1929 , p. 309-324.

- Piedra. Nouvelle pratique dermatologique, II, 1936, p. 377-408.

Instituts Pasteur de Dalat et de Saïgon. 